\title{
Cendestato
}

\section{Relações entre a Teoria das Necessidades Psicológicas Básicas e a competência em informação}

\author{
Adriana Rosecler Alcará \\ Doutora em Psicologia; Departamento Ciência da Informação da Universidade Estadual de Londrina \\ (UEL), Londrina, PR, Brasil; \\ E-mail: adrianaalcara@gmail.com
}

\begin{abstract}
Resumo: Este artigo apresenta relações entre a necessidade de competência, autonomia e pertencimento e a competência em informação. Essas três necessidades integram a Teoria da Autodeterminação e, quando satisfeitas, influenciam na motivação intrínseca, que é essencial para a aprendizagem e inerente à competência em informação. Quanto aos procedimentos, é uma pesquisa bibliográfica, de caráter exploratório e com abordagem qualitativa. Foi feita a partir de um levantamento bibliográfico no Portal de Periódicos da Coordenação de Aperfeiçoamento de Pessoal de Nível Superior e no Google Acadêmico. Entre os principais resultados, evidencia que a competência em informação pode ser impactada pela competência, autonomia e pertencimento, assim como a satisfação dessas necessidades psicológicas básicas pode ser apoiada pela competência em informação. Isso porque ambas têm em comum aspectos cognitivos, afetivos e sociais que estão presentes nas ações para a formação do aprendiz frente às suas demandas e problemas informacionais. Ressalta que a associação entre a motivação e a competência em informação é necessária e que as variáveis individuais, coletivas e contextuais que podem influenciar a motivação para aprender também implicam em interferências na competência em informação. Assim, deve-se levar em conta essas variáveis no planejamento de ações para a formação da competência em informação.
\end{abstract}

Palavras-chave: Competência em informação. Motivação para aprender. Necessidades psicológicas básicas. Teoria da Autodeterminação. Formação da competência em informação.

\section{Introdução}

Vivemos em um ambiente informacional cada vez mais complexo em que a produção, disponibilização e compartilhamento da informação se apresentam de formas distintas, se dão por meio de recursos variados e são potencializados pelas tecnologias de informação. Consequentemente, isso provoca mudanças e lança novos desafios às pessoas quando buscam e usam a informação. 
Complementarmente a isso, importa destacar que buscar, selecionar, usar e refletir crítica e eticamente sobre a informação são ações determinantes no processo de aprendizagem nos mais diferentes contextos, sejam eles educacionais, organizacionais, culturais, sociais, entre outros. Para desempenhar essas ações, as pessoas precisam de habilidades, que são (ou deveriam ser) desenvolvidas ao longo de sua vida em contextos de formação escolar e acadêmica, de atuação profissional e em sociedade. Seguindo essa ideia de formação de habilidades ao longo da vida, voltamos nosso olhar para a competência em informação, cuja filosofia consiste no aprender a aprender e no aprender durante toda a vida.

Com essa perspectiva de processo de aprendizagem e de aprendizado ao longo da vida, Dudziak (2003, p. 28, grifo do autor) se referiu à competência em informação como "[...] o processo contínuo de internalização de fundamentos conceituais, atitudinais e de habilidades necessário à compreensão e interação permanente com o universo informacional e sua dinâmica [...].”.

Essa visão de Dudziak (2003), quando reflete sobre o aprendizado, se assemelha ao que Anastasiou (2012) destacou a respeito das características dos tipos de conteúdo inerentes ao processo de aprender, que foram elencados por Zabala (1998) e que consistem em três grandes grupos: a) conceituais - o que é preciso saber para aprender; b) procedimentais - o que é preciso saber fazer para aprender; c) atitudinais - como ser; que tipo de comportamento ter para aprender.

Levando isso em conta, ao refletir sobre a competência em informação precisamos nos ater ao processo de aprendizagem, já que o mesmo pode ser potencializado por ela. Assim sendo, a competência em informação pode ser vista como um conjunto de habilidades que a pessoa precisa desenvolver para lidar com a informação, sendo elas cognitivas, que se referem ao conteúdo, aos saberes, ao conhecimento, procedimentais, que envolvem as estratégias adotadas para aprender o conteúdo, e atitudinais, que dizem respeito à disposição da pessoa para aprender, que é impactada pelas suas vivências, crenças e valores. É a combinação desses três tipos de habilidades que vai possibilitar com que nos relacionemos e interagimos de forma consciente e reflexiva com a informação, com vistas ao aprendizado e a construção de conhecimento.

Nesse sentido, a competência em informação incorpora processos de aprendizagem voltados à informação. Essa concepção é destacada por Bruce 
(2013) quando discute a aprendizagem informacional, que consiste em experimentar diferentes formas de utilizar a informação para aprender e é nessa perspectiva que ela associa essa aprendizagem à competência em informação.

O processo de aprendizagem também está entre as perspectivas conceituais da competência em informação elencadas por Mata (2018). Segundo essa autora (MATA, 2018), conceitualmente a competência em informação pode ser vista a partir de três vieses, a saber: conjunto de competências (habilidades para lidar adequadamente com a informação), processo de ensino e aprendizagem (ações e programas que visam a formação de saberes e habilidades informacionais) e área disciplinar (conjunto de padrões, indicadores, documentos, eventos, grupos de pesquisa, entre outros).

Atualmente, nossas reflexões têm se voltado mais para o segundo viés, isso porque mais do que identificar quais habilidades são necessárias para a competência em informação ou qual conjunto de habilidades a pessoa precisa ter para lidar com a busca, uso e compartilhamento da informação, precisamos nos atentar às dificuldades que as pessoas têm em praticar a competência em informação no seu dia a dia. Mais ainda, o que elas precisam em relação às suas habilidades para solucionar as dificuldades e como podemos promovê-las por meio de ações de formação.

Nesse contexto, nossas intenções de pesquisa têm se concentrado na compreensão das ações necessárias à formação da competência em informação. De modo que, considerando que o processo de aprender é inerente à competência em informação, cabe-nos investigar quais variáveis interferem nesse aprendizado. Dentre essas variáveis podemos destacar a disposição para aprender e a internalização quanto à sua importância, que estão diretamente relacionadas à motivação da pessoa.

A pessoa motivada busca novos conhecimentos e oportunidades, envolvese nas atividades com entusiasmo e demonstra disposição para enfrentar os desafios. Desse modo, a motivação tem implicações diretas na qualidade do envolvimento da pessoa com o processo de aprendizagem e, consequentemente, na competência em informação, já que essa requer o desenvolvimento de habilidades diversas, assim como a disposição para aprender continuamente. 
Existem diversas teorias que fornecem subsídios para estudar a motivação e os aspectos que a influenciam, como por exemplo a Teoria das Necessidades Psicológicas Básicas, que integra a Teoria da Autodeterminação (TAD) (Self Determination Theory - SDT). A TAD foi desenvolvida por Deci e Ryan na década de 1970, com o propósito de “[...] compreender os determinantes motivacionais e descobrir contextos promotores das formas autodeterminadas de motivação [...]” (GUIMARÃES; BORUCHOVITCH, 2004, p. 144) que são condicionantes ao processo de aprender.

A Teoria das Necessidades Psicológicas Básicas consiste na necessidade de competência, necessidade de autonomia e necessidade de pertencer (pertencimento ou vínculo). Em relação a essa teoria, Ryan e Deci (2017) evidenciam que cada pessoa tem internamente uma tendência natural ao crescimento e desenvolvimento. No entanto, embora natural, essa tendência também sofre influências, portanto, requer apoio social e ambiental para que as pessoas satisfaçam as suas necessidades psicológicas básicas e tenham orientações motivacionais autodeterminadas.

A questão motivacional é pouco abordada em pesquisas da competência em informação (especialmente em âmbito nacional). Fazzioni, Vianna e Vitorino (2018, p. 204) indicam “[...] uma lacuna de estudos na temática da competência em informação, relacionada à questão emocional e afetiva", o que também justifica a intencionalidade em relação a essa temática.

Dessa forma, este estudo tem como objetivo apresentar relações teóricas entre a necessidade de competência, autonomia e pertencimento e a competência em informação. A pesquisa é bibliográfica, de caráter exploratório e com abordagem qualitativa. Foi feita a partir de um levantamento bibliográfico, em meados de 2020, no Portal de Periódicos da Coordenação de Aperfeiçoamento de Pessoal de Nível Superior (CAPES) e no Google Acadêmico, sem recorte temporal, nos idiomas português, inglês e espanhol, tendo como palavras-chave: competência em informação, competência informacional, information literacy, motivação para aprender e Teoria da Autodeterminação combinados, quando necessário, com operadores booleanos.

Vale salientar que este estudo representa um ensaio inicial, com resultados teóricos preliminares, e integra uma pesquisa maior, que está em andamento no 
âmbito do grupo de pesquisa que coordenamos. Tal pesquisa tem entre os seus objetivos explorar diferentes teorias da motivação, assim como a metacognição, acreditando que ambas possam atuar como pano de fundo nas ações da competência em informação em contextos variados, envolvendo estudantes de diferentes níveis de ensino, bibliotecários e pessoas em situação de vulnerabilidade. O presente texto foi estruturado a partir de uma breve contextualização histórica e conceitual da competência em informação, seguida da apresentação a respeito da motivação e da Teoria das Necessidades Psicológicas Básicas e suas possíveis relações com a competência em informação.

\section{Competência em informação: breve contextualização histórica e conceitual}

Resumidamente, podemos dizer que a competência em informação ainda é uma área de estudos recente, considerando o tempo de seu surgimento. De acordo com Dudziak (2003), a primeira menção à competência em informação ocorreu nos Estados Unidos, em 1974, referida como information literacy ${ }^{1}$ pelo bibliotecário Paul Zurkowsky, então presidente da Information Industry Association. Nesse período, o foco da competência em informação era voltado ao aprendizado das pessoas no uso de recursos informacionais, tendo uma ênfase mais instrumental. Em seguida, a visão e perspectiva para a competência em informação foi se ampliando e incluindo diferentes contextos além da indústria, como por exemplo, em 1976 - informação para a cidadania; 1983 - bibliotecas e educação; 1987 integração aos currículos (DUDZIAK, 2003).

É nesse momento também que surge uma definição proposta pela American Library Information (ALA) e que passou a ser universalmente utilizada nas publicações sobre o tema. Segundo a ALA (1989) para ser competente em informação a "[...] pessoa deve ser capaz de reconhecer quando as informações são necessárias e ter a capacidade de localizar, avaliar e usar efetivamente as informações necessárias." (ALA, 1989, p. 1, tradução nossa). A ALA (1989) complementa que, para a formação dessa pessoa, será necessário que as instituições de ensino integrem o conceito de competência em informação em suas 
atividades de aprendizagem. Isso porque as pessoas com formação para a informação são aquelas que aprenderam a aprender. Elas

[...] sabem aprender porque sabem como o conhecimento é organizado, como encontrar informações e como usar as informações de maneira que outras pessoas possam aprender com elas. São pessoas preparadas para a aprendizagem ao longo da vida [...] (ALA, 1989, p. 1, tradução nossa).

Na visão de Dudziak (2003), a partir dos anos de 1990, a competência em informação ganha maior visibilidade mundialmente, disseminando-se nos vários continentes, com uma busca constante pela maior compreensão do conceito, de modo a "[...] torná-la acessível a um número cada vez maior de pessoas." (DUDZIAK, 2003, p. 28). Belluzzo (2018) e Dudziak (2003) indicam que, no Brasil, os primeiros estudos surgem no início dos anos 2000, com as pesquisas de Caregnato (2000), Belluzzo (2001), Dudziak (2001), Hatschbach (2002) e Campello (2003).

Dudziak (2003) destaca que a competência em informação tem como objetivo formar pessoas que saibam definir suas necessidades de informação, que conheçam as diversas fontes de informação, que avaliem, usem e compartilhem a informação observando os aspectos éticos, que sejam aprendizes independentes e que aprendam ao longo da vida. Podemos perceber nessa perspectiva a presença de diferentes aspectos cognitivos e afetivos da pessoa ao lidar com a informação.

Atualmente, são inúmeras as produções mundiais sobre o tema, envolvendo também um número grande de pesquisadores e profissionais que se dedicam a estudá-la com foco na avaliação e proposição de modelos, esquemas e estruturas voltados à formação de habilidades para a competência em informação. Belluzzo (2018) salienta que a representatividade da competência em informação também foi influenciada por um conjunto de declarações e manifestos ${ }^{2}$ elaborados por diferentes organismos nacionais e internacionais. Vale enfatizar que esses materiais sinalizam a importância do desenvolvimento da competência em informação nos mais diferentes âmbitos da sociedade e orientam para que profissionais, pesquisadores e instituições promovam ações em prol de uma sociedade mais justa e equitativa a partir do acesso e uso crítico, reflexivo e consciente da informação. 
Além disso, há que se destacar ainda os diversos modelos teóricos e documentos, tais como indicadores, padrões e diretrizes para a avaliação e desenvolvimento da competência em informação, propostos por pesquisadores, instituições e demais organismos. Furtado e Alcará (2015) e Spudeit (2016) apresentam um panorama com os principais modelos, padrões e documentos e descrevem as características de cada um deles, com o objetivo de subsidiar o planejamento de ações mais efetivas na formação da competência em informação.

No que se refere aos padrões e diretrizes, é importante citar a ALA e a Association of College and Research Libraries (ACRL) que, ao longo desses últimos 20 anos, elaboraram vários documentos que se tornaram referências mundiais, como é o caso do Information Literacy Competency Standards for Higher Education (ALA, 2000). Mais recentemente, os indicadores listados nesse documento foram revisados e, tendo em vista uma versão com opções consideradas por elas mais flexíveis, foram substituídos pelo Framework for Information Literacy for Higher Education (ACRL, 2016),

Junto a esse novo documento, a ACRL traz ainda uma nova proposta conceitual para a competência em informação, que a evidencia como um conjunto de habilidades integradas, englobando uma abordagem reflexiva da informação, o entendimento de como a informação é produzida e valorizada, o uso da informação na criação de novos conhecimentos e a participação ética nas comunidades de aprendizagem (ACRL, 2016). Nesse documento, estão descritos conceitos que são interligados e dão base para a implementação de ações para a competência em informação. Cada um desses conceitos traz metas de aprendizagem que são ilustradas por dois elementos, denominados de práticas de conhecimento e disposições. As práticas de conhecimento referem-se à demonstração de maneiras ou habilidades pelas quais os estudantes podem melhorar a sua compreensão dos conceitos. E as disposições constituem-se de um conjunto de atitudes, preferências e intenções; representam uma tendência para agir ou pensar de alguma forma particular.

Vemos que a descrição das disposições está muito próxima da motivação, reforçando a necessidade de investigarmos as variáveis individuais, coletivas ou contextuais que podem influenciar a motivação para aprender e sua interferência na competência em informação. No que se refere a essa nova proposta conceitual, 
podemos também destacar aspectos que são fundamentais aos processos de aprendizagem, tais como a abordagem reflexiva, a compreensão de como a informação é produzida, a questão da ética, enfim, são ações que vão demandar da pessoa aquele conjunto de habilidades cognitivas, procedimentais e atitudinais já abordado anteriormente.

Pelo exposto, percebemos que a competência em informação envolve uma complexidade de fatores e é multidimensional, conforme apontado por Vitorino (2016) e Vitorino e Piantola (2011). Seu conceito precisa ser continuamente refletido e atualizado e, quando aplicado ao ambiente informacional das pessoas, precisa levar em conta as suas experiências anteriores, os seus recursos, o seu contexto, as suas crenças, o seu estilo de aprendizagem, a sua disposição para aprender, entre outros aspectos.

Nessa mesma linha, Corrêa e Castro Júnior (2018) observam que a evolução do conceito da competência em informação reflete as variáveis do contexto no qual ela se insere. Isso fica mais evidente quando percebemos que a competência em informação evoluiu de uma abordagem centrada no indivíduo para uma perspectiva mais sociológica ou sociocultural.

Assim sendo, acreditamos que, além dos fatores internos de cada pessoa, situações externas como, por exemplo, o contexto em que a pessoa esteja inserida, exercem influência nas ações e decisões individuais e coletivas. Por isso a relevância de refletir sobre como promover a autonomia, a competência e o pertencimento, que se constituem em subsídios para o melhor relacionamento da pessoa com o seu meio e, consequentemente, impactando na motivação e na competência em informação.

\section{A motivação na perspectiva das necessidades psicológicas básicas da Teoria da Autodeterminação}

A motivação leva a pessoa a fazer escolhas e a instiga a ter determinado comportamento, implicando diretamente em suas ações. Envolve um conjunto de fatores e, quando motivada, a pessoa tende a buscar novos conhecimentos e 
oportunidades, envolve-se com as atividades e supera com mais facilidade os desafios que se apresentam.

De forma geral, Bzuneck (2004) apresenta a motivação como sendo "[...] aquilo que move uma pessoa ou que a põe em ação ou a faz mudar o curso." (BZUNECK, 2004, p. 9). Com o objetivo de compreender melhor a motivação, Maehr e Meyer (1997) se reportam a ela como um investimento pessoal e, para isso, as pessoas precisam dispor de alguns recursos como, por exemplo, tempo, energia, talentos, conhecimentos e habilidades, que podem ser aplicados nas várias atividades a serem desenvolvidas, seja no trabalho, nos estudos, no lazer ou em qualquer outra situação. Esse investimento pessoal impactará nas atividades e a sua manutenção ocorre enquanto os fatores motivacionais estiverem atuando.

Os fatores motivacionais podem ser caracterizados em internos, que têm origem na própria pessoa, e externos, que são decorrentes de intervenções de outros ou do ambiente em que a pessoa esteja inserida. Eles são estudados na perspectiva da motivação intrínseca e extrínseca.

A motivação intrínseca, também denominada autônoma ou autodeterminada, consiste na disposição natural e espontânea da pessoa para se envolver com as atividades em um dado contexto. De acordo com Guimarães (2004), “A motivação intrínseca refere-se à escolha e realização de determinada atividade por sua própria causa, por esta ser interessante, atraente ou, de alguma forma, geradora de satisfação.” (GUIMARÃES, 2004, p. 37). Já a motivação extrínseca (motivação controlada) é considerada

[...] como a motivação para trabalhar em reposta a algo externo à tarefa ou atividade, como para a obtenção de recompensas materiais ou sociais, de reconhecimento, objetivando atender aos comandos ou pressões de outras pessoas [...] (GUIMARÃES, 2004, p. 46).

Esses dois tipos de motivação, inicialmente, eram estudados de modo dicotômico, sendo uma em oposição à outra. No entanto, com o aprofundamento das pesquisas, essa ideia foi revista e os autores (DECI; RYAN, 2000; RYAN; DECI, 2000a) passaram a perceber que os comportamentos extrinsecamente motivados, que eram vistos apenas como prejudiciais à motivação, também poderiam se tornar autônomos ou autodeterminados e, dessa forma, contribuírem 
para o envolvimento natural da pessoa com a situação de aprendizagem. Isso porque, no decorrer de determinada atividade, mesmo tendo uma orientação inicial extrínseca, a pessoa pode perceber o valor da atividade, o quanto ela é importante para si e passar a realizá-la de modo intrínseco, gerando assim satisfação e prazer. A base para o avanço nessas pesquisas foi a ideia de internalização ou autorregulação dos comportamentos e os fatores que neles impactam, que passaram a ser estudados em um continuum da autodeterminação ${ }^{3}$, proposto por Ryan e Deci (2000a, 2000b).

Pelo exposto, percebemos que, assim como a competência em informação, a motivação é um construto complexo, que envolve diferentes fatores internos relacionados à pessoa e elementos do contexto ou situação em que ela esteja inserida. Considerando essa complexidade, existem diversas teorias ${ }^{4}$ que fornecem subsídios para se estudar a motivação e os aspectos que a influenciam. Neste artigo, conforme já mencionado, baseamo-nos na Teoria da Autodeterminação (TAD), proposta por Deci e Ryan na década de 1970.

A TAD é considerada uma macro teoria da motivação composta por seis mini teorias - Teoria da Avaliação Cognitiva (estuda como as condições socioculturais tendem a promover ou diminuir a motivação intrínseca das pessoas), Teoria das Orientações de Causalidade (seu foco está na compreensão das diferenças individuais resultantes das interações da pessoa com o ambiente social em que vive), Teoria da Integração Organísmica (estuda formas distintas de motivações extrínsecas ao longo de um continuum da autodeterminação com diferentes níveis de regulação), Teoria das Necessidades Psicológicas Básicas (reflete sobre contextos que satisfazem ou ameaçam as necessidades de autonomia, competência e vínculo), Teoria do Conteúdo das Metas (destaca que as pessoas internalizam e adotam diferentes objetivos e aspirações da vida que impactam em grande parte nas suas atitudes e comportamentos do dia a dia) e Teoria Motivacional dos Relacionamentos (se preocupa com os vínculos afetivos essenciais ao bem-estar individual) (DECI; RYAN, 2000, 2002; REEVE; DECI; RYAN, 2004; RYAN; DECI, 2017, 2019).

Cada mini teoria analisa diferentes aspectos do mesmo fenômeno (a motivação) e o seu conjunto amplia a compreensão da motivação e possibilita investigar como as tendências naturais para o crescimento e as necessidades 
psicológicas interagem com as condições socioculturais. Ryan e Deci (2019) ressaltam que essas mini teorias surgiram organicamente no âmbito da TAD, conforme seus estudos avançaram. Complementar a isso, Ryan e Deci (2020) enfatizam que a TAD é uma ampla estrutura para a reflexão dos fatores que facilitam ou dificultam a motivação intrínseca, a motivação extrínseca autônoma e o bem-estar psicológico, sendo essas questões de relevância direta para os ambientes educacionais, por exemplo.

Dentre essas mini teorias, como já dito na introdução, selecionamos a Teoria das Necessidades Psicológicas Básicas, que será foco das reflexões e relações com a competência em informação neste texto. Essa Teoria das Necessidades Psicológicas Básicas tem como objetivo entender os fatores que promovem ou não a satisfação das três necessidades: autonomia, competência e vínculo (pertencimento), que, segundo Guimarães e Boruchovitch (2004), se constituem em nutrientes para o relacionamento efetivo e saudável das pessoas com o seu meio (contexto). Guimarães e Boruchovitch (2004) ainda evidenciam que na perspectiva dessa teoria, quando satisfeitas, essas três necessidades tendem a influenciar positivamente no crescimento, integração e bem-estar pessoal.

A necessidade de autonomia refere-se às ações e comportamentos autônomos ou autodeterminados que se concretizam quando as pessoas acreditam que podem realizar determinada atividade ou fazer escolhas por vontade própria, sem a necessidade de algum elemento externo. Legault (2017) afirma que a autonomia está relacionada às ações e à tomada de decisões conscientes que a pessoa realiza, de acordo com seus valores, princípios, interesses, vontades e crenças pessoais.

Ryan e Deci (2020) reforçam sua concepção de que a autonomia só será promovida quando a pessoa tiver a oportunidade de escolhas autodirigidas e realizar ações que tenham uma causa internalizada. Isto é, que ela esteja consciente da importância de realizar aquela ação. $\mathrm{O}$ apoio à autonomia leva a uma maior internalização da aprendizagem, maior engajamento e maior envolvimento. Nesse sentido, reportando-se ao contexto acadêmico, esses mesmos autores (RYAN; DECI, 2020) indicaram algumas ações que o professor pode realizar tendo em vista a promoção da autonomia dos estudantes, como por exemplo: compreender, reconhecer e procurar atender interesses e expectativas 
dos estudantes; oferecer oportunidades para que eles tenham iniciativas em relação aos seus trabalhos acadêmicos (senso de iniciativa); apresentar o valor e a justificativa para as atividades propostas; dar condições para que eles experimentem oportunidades de escolha; criar situações e ambientes que possibilitem oportunidades de crescimento; respeitar e tentar apreciar a perspectiva e os desafios únicos enfrentados por cada estudante. Segundo Ryan e Deci (2020), ao receberem esse apoio, os estudantes tendem a se sentir mais seguros e ter a percepção de satisfação em relação à necessidade de autonomia.

Sobre a necessidade de competência, Deci e Ryan (2000) e Ryan e Deci (2000b, 2002) afirmam que, quando satisfeita, ela conduz a pessoa a prosseguir em suas atividades e a buscar novos desafios, assim como quando a pessoa percebe que fez algo com eficiência ou que tenha alcançado o objetivo estabelecido tem a necessidade satisfeita. Refletindo sobre o contexto educacional, Deci e Ryan (2000) e Ryan e Deci (2000b, 2002) acrescentam que, quando o estudante acredita na sua competência, ele tende a internalizar e estabelecer objetivos de aprendizagem e isso não se refere a uma habilidade ou capacidade adquirida, mas a uma sensação de segurança e confiança no desenvolvimento das ações.

Guimarães e Boruchovitch (2004) mencionam que ofeedback positivo que a pessoa recebe em situações de desafios fortalece a percepção de competência e promove a motivação intrínseca, porém, é necessário que a competência seja também acompanhada pela percepção de autonomia, já que essa fará com que a pessoa se sinta responsável e com senso de liberdade pelo seu desempenho competente. As autoras complementam que "[...] as circunstâncias que promovem a percepção de autonomia e de competência, denominadas informativas, são promotoras da motivação intrínseca." (GUIMARÃES; BORUCHOVITCH, 2004, p. 146).

A terceira necessidade - a de pertencimento - é considerada o pano de fundo para a autonomia e a competência. Também chamada de necessidade de pertencer, consiste no estabelecimento de vínculos com os outros, que fazem a pessoa se sentir parte de um contexto. De acordo com Ryan e Deci (2002), essa necessidade reflete a tendência de a pessoa estar integrada, conectada e aceita pelos outros. Quando satisfeita, ela gera a sensação psicológica de estar em 
unidade ou comunhão segura em relação aos integrantes do contexto em que esteja inserida. Mais recentemente, Vansteenkiste, Ryan e Soenens (2020) apontaram que o relacionamento denota a experiência de cordialidade, vínculo e cuidado, e tende a ser satisfeito quando a pessoa se conectar e sentir-se significativa com os outros. Por outro lado, a frustração do relacionamento vem acompanhada de sentimentos de alienação social, exclusão e solidão.

Legault (2017) argumenta que, para crescerem psicologicamente e se desenvolverem, as pessoas buscam e precisam de autonomia, isto é, precisam se sentir livres e autodirigidas (autodeterminadas). Além disso, também necessitam de competência, que é a percepção de eficácia nas interações com o meio ambiente e da sensação de estarem significativamente conectadas, integradas com os outros, fortalecendo a percepção de proximidade. Segundo Legault (2017), essas três necessidades são orgânicas e há uma tendência de nos sentirmos inerentemente ligados e dependentes do contexto para a nossa sobrevivência, já que é ele que fornecerá os nutrientes necessários para o nosso desenvolvimento. Legault (2017) enfatiza ainda que, assim como os organismos possuem as necessidades fisiológicas de sede, fome e sono - que devem ser atendidas por ambientes que fornecem água, alimento e abrigo para que sobrevivam -, os organismos também têm necessidades psicológicas importantes para se adaptarem e funcionarem de maneiras saudáveis.

Após duas décadas de pesquisas, Vansteenkiste, Ryan e Soenens (2020) evidenciaram que os estudos sobre as necessidades psicológicas básicas são ativos e crescentes, pois abordam questões teóricas fundamentais sobre a natureza humana e trazem implicações práticas de longo alcance para pais, educadores, gerentes, treinadores e demais atores sociais. Segundo Vansteenkiste, Ryan e Soenens (2020), a preocupação com as necessidades psicológicas básicas também tem implicações na (re)organização de escolas e locais de trabalho, bem como no desenvolvimento de políticas sustentáveis de assistência à saúde e bem-estar.

Essa reflexão bastante recente de Vansteenkiste, Ryan e Soenens (2020) nos incita a continuar na trilha de inter-relações entre as necessidades psicológicas básicas e a competência em informação. Isso fica ainda mais aparente quando olhamos para o Manifesto de Florianópolis sobre a competência em informação, que a apresenta como um direito fundamental à pessoa, intrínseco ao seu próprio 
ser e essencial à sua sobrevivência (MANIFESTO..., 2013). Assim como na Carta de Marília (2014), em que foi reafirmada a relevância da competência em informação para o desenvolvimento social e humano. Da mesma forma, no Global Media and Information Literacy proposto pela Organização das Nações Unidas para a Educação, a Ciência e a Cultura (UNESCO) em 2016, que, de acordo com Dudziak, Ferreira e Ferrari (2017), trata da competência em informação e em mídia e está voltado ao empoderamento e cidadania a partir da mobilização de um conjunto integrado de conhecimentos, habilidades e atitudes.

4 Na trilha de aproximações: competência em informação e a Teoria das Necessidades Psicológicas Básicas

A ideia de aprendizagem e de aprender ao longo da vida requerida e promovida pela competência em informação é influenciada pelas necessidades psicológicas básicas. Assim como a satisfação das três necessidades pode ser apoiada pela competência em informação, já que ambas as abordagens têm em comum a internalização, as ações autorreguladas e independentes, a interação, o compartilhamento, o desejo de conhecer, as crenças, tendo como direção e foco o processo de aprender.

A autonomia, a competência e o pertencimento promovem a motivação para aprender e recebem influências da competência em informação, que também será impactada por elas, já que, quando satisfeitas as necessidades de pertencimento, autonomia e de competência, a pessoa tende a ficar motivada para buscar e usar a informação de forma mais consciente e reflexiva, desenvolvendo assim a sua competência em informação. Aqui também precisamos acrescentar que a aprendizagem não ocorre apenas de forma individualizada, mas principalmente na interação do aprendiz com os outros e com os elementos do contexto em que ele esteja inserido. Nessa interação, o vínculo ou pertencimento promovem a percepção de fazer parte e favorecem a autoconfiança do aprendiz.

Essa relação da motivação com a competência em informação já vem sendo investigada em alguns estudos estrangeiros, como por exemplo Crow (2006, 2007), em que destaca que a motivação intrínseca está no cerne da 
competência em informação, tornando-se base para o desejo de aprender e de encontrar informações de forma independente. Para tanto, de acordo com Crow (2006, 2007), precisamos apresentar estratégias de ensino e ambientes de aprendizagem que ajudem os estudantes não apenas a aprender na escola, mas mostrar a eles a importância de ter atitudes para a aprender durante toda sua vida.

Maybee e Flierl (2016) também já pesquisaram sobre a autonomia, a competência e o pertencimento e seu papel em atividades de aprendizagem informacional. Inclusive, esses autores propuseram um modelo que pode ser usado por bibliotecários ao trabalhar com professores em sala de aula para promover maior aprendizagem do estudante a partir do engajamento criativo e reflexivo com as atividades de formação (MAYBEE; FLIERL, 2016). Entre os resultados do estudo, Maybee e Flierl (2016), descreveram características de atividades de aprendizagem motivadoras e que promovem o envolvimento dos estudantes com a informação.

Outra aproximação da competência em informação com as necessidades psicológicas básicas pode ser estabelecida a partir do seu entendimento como um processo de ensino e aprendizado e sua aplicabilidade levando-se em conta as orientações indicadas por Ryan e Deci (2020). Nesse caso, os ambientes de formação da competência em informação, seja a partir de ações de professores ou de bibliotecários, precisam contar com atividades que promovam nos aprendizes a autonomia e a independência, com escolhas e atitudes conscientes, internalizadas e autodirigidas. Considerando para isso as expectativas e interesses dos aprendizes, o senso de iniciativa, a valorização e a significação da atividade a ser proposta, além da criação de situações que oportunizem crescimento, entre outros.

Essas reflexões iniciais fortalecem e intensificam as inter-relações entre as necessidades psicológicas básicas, a motivação e a competência em informação. Vale aqui também relatar algumas experiências de pesquisas nacionais já realizadas que, apesar de ainda em quantidade bastante incipiente, apresentam dados que revelam algumas pistas que podem colaborar para a atuação dos professores em sala de aula e de bibliotecários na promoção da aprendizagem por meio da informação, assim como no planejamento de ações para a formação da competência em informação. 
Um primeiro exemplo foi o estudo de Akaichi, Tomaél e Alcará (2016), que teve como objetivo identificar os fatores que influenciam as ações dos coordenadores dos Programas de Pós-Graduação em Ciência da Informação do Brasil. Entre as condições analisadas, estavam as percepções dos coordenadores em relação às três necessidades psicológicas básicas. De forma geral, os resultados apontaram que a maioria dos coordenadores que participaram do estudo tinha as necessidades de competência e de pertencimento satisfeitas. Porém, no que diz respeito à autonomia, os participantes da pesquisa de Akaichi, Tomaél e Alcará (2016) indicaram que essa necessidade precisava ser mais desenvolvida e que a falta da percepção de autonomia poderia interferir no envolvimento e nas atividades dos coordenadores, no que diz respeito ao compartilhamento da informação e do conhecimento.

Outra pesquisa foi a de Miranda, Pereira e Alcará (2019) que buscou relações teóricas da metacognição e da motivação com a competência em informação a partir de uma descrição da motivação intrínseca e extrínseca na perspectiva da Teoria da Autodeterminação. Com base no estudo da literatura, as autoras constataram a relevância da motivação para as ações de formação da competência em informação, isso porque ao estar " [...] motivada de forma intrínseca a pessoa tende a se envolver de modo espontâneo e consciente com as atividades e isso pode promover o desejo de conhecer e de aprender." (MIRANDA; PEREIRA; ALCARÁ, 2019, p. 172).

Com o objetivo de investigar a competência em informação dos pais de surdos, Pereira e Alcará (2020) buscaram também compreender como ela pode contribuir para atender a necessidade de pertencimento. A pesquisa de Pereira e Alcará (2020) foi realizada com 34 pais de surdos que tinham filhos matriculados em duas instituições especializadas na área da surdez na região norte do Paraná. Entre os principais resultados relativos ao pertencimento, os dados apontaram que a maioria dos pais se sentia pertencente à comunidade surda e que esse sentimento favorecia a aproximação, o vínculo, a participação na vida dos filhos, assim como o diálogo com outros familiares de surdos. Os pais ainda mencionaram que esse sentimento de pertencimento é favorecido pelas informações que eles possuem e que esse conhecimento se torna um elo com os demais, que são vistos como fontes de informação sobre a surdez e os ajudam a aprender a lidar com a condição de 
seus filhos. Nesse sentido, Pereira e Alcará (2020) concluíram que a necessidade de pertencimento dos pais de surdos contribui para a competência em informação ao ampliar as habilidades e os laços afetivos.

Em síntese, a motivação e sua relação com a competência em informação e as variáveis que promovem a autonomia, a competência e o pertencimento são questões relevantes a serem discutidas, tanto em pesquisas teóricas quanto empíricas. Essa lacuna de estudos da competência em informação em relação à questão emocional e afetiva, conforme mencionado anteriormente, também aponta para uma tendência de estudos com essa perspectiva.

\section{Algumas considerações}

Para finalizar, ressaltamos que a associação entre a motivação e a competência em informação é necessária, sendo que a promoção e a satisfação das necessidades de autonomia, competência e pertencimento se constituem em uma estratégia relevante. Entretanto, precisamos ter a clareza da complexidade inerente a elas (motivação e competência em informação), já que ambas são dependentes de aspectos cognitivos, afetivos e sociais, que devem estar contextualizados ao ambiente de atuação e de relações em que o sujeito informacional esteja inserido, seja ele estudante, profissional ou outro cidadão.

Fica também evidente que as variáveis individuais, coletivas e contextuais que podem influenciar a autonomia, a competência e o pertencimento também implicam em interferências na competência em informação. Nesse sentido, mais uma vez precisamos refletir sobre o contexto e a necessidade do outro e levar em conta essas variáveis ao planejar ações que oportunizem aos aprendizes o desenvolvimento de sua competência em informação, tendo em vista a sua autonomia e autorregulação na resolução de problemas informacionais ao longo de sua formação e futura prática profissional.

Ademais, enfatizamos que este estudo, ainda em fase exploratória, visa promover um debate inicial entre as questões da motivação e suas relações com a competência em informação, tendo a certeza da necessidade de pesquisas futuras que ampliem o escopo das reflexões aqui apresentadas. Algumas já estão em 
andamento, com objetivos voltados ao mapeamento de outros estudos que relacionaram a competência em informação com as diferentes teorias da motivação, especialmente na produção científica internacional.

\section{Referências}

ACRL. Framework for information literacy for higher education. Chicago: ACRL, 2016.

AKAICHI, T.; TOMAÉL, M. I.; ALCARÁ, A. R. Compartilhamento da informação e do conhecimento: fatores motivacionais que influenciam os coordenadores dos PPGCI. In: COLÓQUIO EM ORGANIZAÇÃO, ACESSO E APROPRIAÇÃO DA INFORMAÇÃO E DO CONHECIMENTTO, 1., 2016, Londrina. Anais [...]. Londrina: UEL, 2016. p. 75-89.

\section{ALA. Information literacy competency standards for higher education.} Chicago: ACRL, 2000.

ALA. Presidential committee on information literacy: final report. Washington: ALA, 10 Jan. 1989.

AMES, C. Classrooms: goals, structures and student motivation. Journal of Educational Psychology, Washington, v. 84, n. 3, p. 261-271, 1992.

ANASTASIOU, L. G. C. Ensinar, aprender, apreender e processos de ensinagem. In: ANASTASIOU, L. das G. C.; ALVES, L. P. Processo de ensinagem nas universidades: pressupostos para as estratégias de trabalho em aula. Joinvile: Univille, 2012. p. 15-44.

BANDURA, A. Self-efficacy: toward a unifying theory of behavioral change. Psychological Review, Washington, v. 84, n. 2, p. 191-215, 1977.

BELLUZZO, R. C. B. A competência em informação no Brasil: cenários e espectros. São Paulo: ABECIN, 2018.

BELLUZZO, R. C. B. A information literacy como competência necessária à fluência científica e tecnológica na sociedade da informação: uma questão de educação. In: SIMPÓSIO DE ENGENHARIA DE PRODUÇÃO DA UNESP, 7., 2001, Bauru. Anais [...]. Bauru: UNESP, 2001. p. [1-7].

BRUCE, C. S. El aprendizaje informado. Boletín de la Asociación Andaluza de Bibliotecarios, Málaga, n. 105, p. 92-112, 2013.

BZUNECK, J. A. A motivação do aluno: aspectos introdutórios. In: BORUCHOVITCH, E.; BZUNECK, J. A. (org.). A motivação do aluno: contribuições da psicologia contemporânea. 3. ed. Petrópolis: Vozes, 2004. p. 936. 
CAMPELLO, B. S. O movimento da competência informacional: uma perspectiva para o letramento informacional. Ciência da Informação, Brasília, v. 32, n. 3, p. 28-37, 2003.

CAREGNATO, S. E. O desenvolvimento de habilidades informacionais: o papel das bibliotecas universitárias no contexto da informação digital em rede.

Revista de Biblioteconomia \& Comunicação, Porto Alegre, v. 8, p. 47-55, 2000.

CARTA de Marília. In: SEMINÁRIO DE COMPETÊNCIA EM

INFORMAÇÃO: cenários e tendências, 3., 2014, Marília. Anais [...]. Marília: UNESP, 2014. p. 1-2.

CORRÊA, E. C. D.; CASTRO JÚNIOR, O. V. de. Perspectivas sobre competência em informação: diálogos possíveis. Ciência da Informação, Brasília, v. 47, n. 2, p. 35-51, 2018.

CROW, S. R. Information literacy: what's motivation got to do with it? Knowledge Quest, Chicago, v. 35, n. 4, p. 48-52, 2007.

CROW, S. R. What motivates a lifelong learner? School Libraries Worldwide, Jefferson City, v. 12, n. 1, p. 22-34, 2006.

DECI, E. L.; RYAN, R. M. Self-determination research: reflections and future direction. In: DECI, E. L.; RYAN, R. M. (ed.). Handbook of self-

determination research. Rochester: University of Rochester Press, 2002. p. 431-441.

DECI, E. L.; RYAN, R. M. The "what" and "why" of goal pursuits: human needs and the self-determination of behavior. Psychological Inquiry, United Kingdom, v. 11, n. 4, p. 227-268, 2000.

DECLARAÇÃO de Alexandria sobre alfabetização informacional e a aprendizagem ao longo da vida: faróis para a sociedade da informação. [S. l.]: UNESCO, 2005.

DECLARAÇÃO de Havana sobre 15 ações de competência em informação/ ALFIN [...]. Havana: [s. n.], 2012.

DECLARATORIA de Lima: Taller de alfabetización informacional: formando a los formadores. Lima: UNESCO, 2009.

DECLARAÇÃO de Lyon sobre o acesso à informação e desenvolvimento. França: IFLA, 2014.

DECLARAÇÃO de Maceió sobre competência em informação. Maceió: IBICT, 9 ago. 2011. 
DECLARACIÓN de Moscú sobre Alfabetización Mediática e Informacional. Moscú: UNESCO, 2012.

DECLARACIÓN sobre la alfabetización informacional (Alfin): bibliotecas por el aprendizaje permanente. [S. l.: s. n.], 2006.

DUDZIAK, E. A. A information literacy e o papel educacional das

bibliotecas. 2001. Dissertação (Mestrado em Ciência da Comunicação) - Escola de Comunicação e Artes, Universidade de São Paulo, São Paulo, 2001.

DUDZIAK, E. A. Information literacy: princípios, filosofia e prática. Ciência da Informação, Brasília, v. 32, n. 1, p. 23-35, 2003.

DUDZIAK, E. A.; FERREIRA, S. M. S. P.; FERRARI, A. C. Competência informacional e midiática: uma revisão dos principais marcos políticos expressos por declarações e documentos. Revista Brasileira de Biblioteconomia e Documentação, São Paulo, v. 13, p. 213-253, 2017.

FAZZIONI, D. P. de M.; VIANNA, W. B.; VITORINO, E. V. O atual estágio conceitual da competência em informação em publicações de língua portuguesa. Ciência da Informação, Brasília, v. 47, n. 3, p. 193-206, 2018.

FEZ declaration on media and information literacy. Fez: Sidi Mohamed Ben Abdellah University Fez, 2011.

FURTADO, R. L.; ALCARÁ, A. R. Desenvolvimento e formação de competência em informação: um mapeamento de modelos, padrões e documentos. In: ENCONTRO NACIONAL DE PESQUISA EM CIÊNCIA DA INFORMAÇÃO, 16., 2015, João Pessoa. Anais [...]. João Pessoa: ANCIB, 2015. p. 1-21.

GUIMARÃES, S. É. R.; BORUCHOVITCH, E. O estilo motivacional do professor e a motivação intrínseca dos estudantes: uma perspectiva da teoria da autodeterminação. Psicologia: reflexão e crítica, Porto Alegre, v. 17, n. 2, p. 143-150, 2004.

GUIMARÃES, S. É. R. Motivação intrínseca, extrínseca e o uso de recompensas em sala de aula. In: BORUCHOVITCH, E.; BZUNECK, A. (org.). A motivação do aluno: contribuições da psicologia contemporânea. 3. ed. Petrópolis: Vozes, 2004. p. 37-57.

HATSCHBACH, M. H. L. Information literacy: aspectos conceituais e iniciativas em ambiente digital para o estudante de nível superior. 2002. Dissertação (Mestrado em Ciência da Informação) - Escola de Comunicação, Universidade Federal do Rio de Janeiro, Rio de Janeiro, 2002. 
LEGAULT, L. Self-Determination Theory. In: ZEIGLER-HILL, V.; SHACKELFORD, T. (ed.). Encyclopedia of personality and individual differences. Cham: Springer International Publishing, 2017. Disponível em: https://www.researchgate.net/publication/317690916_SelfDetermination_Theor y. Acesso em: 4 jun. 2020.

MAEHR, M. L.; MEYER, H. A. Understanding motivation and schooling: where we've been, where we are, and where we need to go. Educational Psychology Review, California, v. 9, n. 4, p. 371-409, 1997.

MANIFESTO de Florianópolis sobre a competência em informação e as populações vulneráveis e minorias. Florianópolis: FEBAB, 9 jul. 2013.

MATA, M. L. da. Competência em informação: questões terminológicas e conceituais. In: GERLIN, M. N. M. (org.). Competência em informação e narrativa numa sociedade conectada por redes. Brasília: UNB, 2018. p. 79105.

MAYBEE, C.; FLIERL, M. Motivating learners through information literacy. West Lafayette: Purdue University Libraries, 2016. Paper 150. Disponível em:

https://docs.lib.purdue.edu/cgi/viewcontent.cgi?article=1159\&context=lib_fsdoc s. Acesso em: 4 jul. 2020.

MIRANDA, A. M. M.; PEREIRA, A. P.; ALCARÁ, A. R. A metacognição e a motivação na competência em informação: um ensaio teórico. In: COLÓQUIO EM ORGANIZAÇÃO, ACESSO E APROPRIAÇÃO DA INFORMAÇÃO E DO CONHECIMENTO, 4., 2019, Londrina. Anais [...]. Londrina: UEL, 2019. p. 161-175.

PEREIRA, A. P.; ALCARÁ, A. R. Competência em informação e necessidade de pertencimento dos pais de surdos. Informação \& Informação, Londrina, v. 25, n. 2, p. 209-234, 2020.

REEVE, J.; DECI, E. L.; RYAN, R. M. Self-determination theory: a dialectical framework for understanding sociocultural influences on student motivation. In: MCINERNEY, D. M.; VAN ETTEN, S. (ed.). Big theories revisited. Greenwich: Information Age Publishing, 2004. cap. 3.

RYAN, R. M.; DECI, E. L. Brick by brick: the origins, development, and future of Self-Determination Theory. In: ELLIOT, A. J. (ed.). Advances in

Motivation Science. [S. l.]: Academic Press, 2019. v. 6, p. 111-156.

RYAN, R. M.; DECI, E. L. Intrinsic and extrinsic motivation from a selfdetermination theory perspective: definitions, theory, practices, and future directions. Contemporary Educational Psychology, Orlando, v. 61, p. 1-11, 2020. 
RYAN, R. M.; DECI, E. L. Overview of self-determination theory: an organismic dialectical perspective. In: DECI, E. L.; RYAN, R. M. (ed.). Handbook of self-determination research. Rochester: University of Rochester Press, 2002. cap. 1.

RYAN, R. M.; DECI, E. L. Self-determination theory: basic psychological needs in motivation, development, and wellness. New York: Guilford Publications, 2017.

RYAN, R. M.; DECI, E. L. Intrinsic and extrinsic motivations: classic definitions and new directions. Contemporary Educational Psychology, Orlando, v. 25, n. 1, p. 54-67, 2000a.

RYAN, R. M.; DECI, E. L. Self-determination theory and the facilitation of intrinsic motivation, social development and well-being. American Psychologist, Washington, v. 55, n. 1, p. 68-78, 2000 b.

SIMONS, J. et al. Placing motivation and future time perspective theory in a temporal perspective. Educational Psychology Review, New York, v. 16, n. 2, p. 121-139, 2004.

SPUDEIT, D. Programas para desenvolvimento de competências informacionais: implementação, metodologias e avaliação. In: ALVES, F. M. M.; CORRÊA, E. C. D.; LUCAS, E. R. de O. Competência em informação: políticas públicas, teoria e prática. Salvador: EDUFBA, 2016. p. 235-278.

VANSTEENKISTE, M.; RYAN, R. M.; SOENENS, B. Basic psychological need theory: advancements, critical themes, and future directions. Motivation and Emotion, Dordrecht, n. 44, p. 1-31, 2020.

VITORINO, E. V.; PIANTOLA, D. Dimensões da competência informacional (2). Ciência da Informação, Brasília, v. 40, n. 1, p. 99-110, 2011.

VITORINO, E. V. Uma matriz para o desenvolvimento da competência em informação, sob o foco das dimensões técnica, estética, ética e política e a partir dos cenários de Brasil, Portugal e Espanha. Tendências da Pesquisa Brasileira em Ciência da Informação, [s. l.], v. 9, n. 2, p. 1-21, 2016.

ZABALA, A. A prática educativa: como ensinar. Porto Alegre: Artmed, 1998.

\title{
Relations between Basic Psychological Needs Theory and information literacy
}

\begin{abstract}
This article presents the relations between the need of competence, autonomy and belonging, and information literacy. These three needs are part of the Self-Determination Theory and when they are satisfied, they influence
\end{abstract}


intrinsic motivation that is essential for learning and inherent in information literacy. Regarding the procedures used, it presents a bibliographic research with an exploratory character and a qualitative approach. The research was based on a bibliographic survey on the CAPES Journal Portal and Google Scholar. Among the main results, it shows that information literacy can be impacted by competence, autonomy and belonging, as well as the satisfaction of these basic psychological needs can be supported by information literacy. This is because both have in common cognitive, affective and social aspects that are present in the actions for the training of the learner in the face of his demands and informational problems. It emphasizes that the association between motivation and information literacy is necessary and that the individual, collective and contextual variables that can influence the motivation to learn also imply interferences in information literacy. Thus, these variables must be taken into account when planning actions for the information literacy training.

Keywords: Information literacy. Motivation to learn. Basic psychological needs. Self-Determination Theory. Information Literacy Training.

Recebido: $23 / 07 / 2020$

Aceito: $21 / 09 / 2020$

\section{Declaração de autoria}

Concepção e elaboração do estudo: Adriana Rosecler Alcará

Coleta de dados: Adriana Rosecler Alcará

Análise e discussão de dados: Adriana Rosecler Alcará

Redação e revisão do manuscrito: Adriana Rosecler Alcará

\section{Como citar}

ALCARÁ, Adriana Rosecler. Relações entre a Teoria das Necessidades Psicológicas Básicas e a competência em informação. Em Questão, Porto Alegre, v. 27, n. 2, p. 346-369, abr./jun. 2021.

Doi: http://dx.doi.org/10.19132/1808-5245272.346-369

1 No Brasil, a tradução de information literacy ocorreu de diferentes maneiras, a saber: alfabetização informacional, letramento informacional, habilidades informacionais, competência informacional e competência em informação. Essa última é a expressão padronizada e indicada para uso no Brasil, a partir das reflexões em eventos da área, tais como o Seminário Competência em Informação: cenários e tendências, realizado em Maceió em 2011 e que resultou na Declaração de Maceió sobre competência em informação (DECLARAÇÃO..., 2011) e o III Seminário de Competência em Informação: cenários e tendências, em 2014, na UNESP de Marília, sendo que, nesse último, inclusive foi recomendada a adoção da sigla CoInfo e indicado no documento Carta de Marília, originado no evento (CARTA..., 2014).

${ }^{2}$ Declaração de Alexandria sobre alfabetização informacional e a aprendizagem ao longo da vida: faróis para a sociedade da informação (2005); Declaración sobre la alfabetización informacional (Alfin): bibliotecas por el aprendizaje permanent (2006); Declaratoria de Lima (2009); Declaração de Maceió sobre competência em informação (2011); Fez declaration on media and information literacy (2011); Declaración de Moscú sobre Alfabetización Mediática e Informacional (2012); Declaração de Havana sobre 15 ações de competência em informação/ 
ALFIN... (2012); Manifesto de Florianópolis sobre a competência em informação e as populações vulneráveis e minorias (2013); Declaração de Lyon (2014); Carta de Marília (2014). A descrição do conteúdo desses documentos foi encontrada em Belluzzo (2018).

${ }^{3} \mathrm{O}$ continuum da autodeterminação não será objeto de discussão neste estudo. No entanto, temos a ciência de que ele tende a contribuir para os estudos da competência em informação, já que, a partir dele, temos subsídios para compreender os diferentes níveis de regulação que impactam a motivação das pessoas e isso pode auxiliar nas ações de formação da competência em informação, que tem como premissa o processo de aprendizagem. Nesse sentido, será objeto de investigação em nossas pesquisas futuras.

${ }^{4}$ Apenas para citar algumas, destacamos as Crenças de Autoeficácia (BANDURA, 1977); as Metas de Realização (AMES, 1992); a Perspectiva de Tempo Futuro (SIMONS et al., 2004), entre outras. 